\title{
Mild Overweight Reduces the Risk of Sarcopenia in Healthy Women
}

\author{
Sylvia Kirchengast*, ${ }^{1}$ and Johannes Huber ${ }^{2}$

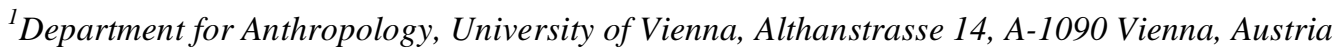 \\ ${ }^{2}$ Medical University Vienna, University Clinic for Gynecology and Obstetrics Währinger Gürtel 18-20 A-1090 Vienna, \\ Austria
}

\begin{abstract}
Background: The process of ageing is accompanied with a progressive decline in skeletal muscle mass resulting in sarcopenia.

Aims: To test the association patterns between body mass index and appendicular skeletal muscle mass adjusted for height and total skeletal muscle mass adjusted for height among healthy women.

Design: In a cross-sectional study the association between body mass index (BMI) and appendicular skeletal muscle mass adjusted for height and total skeletal muscle mass adjusted for height was tested among 834 healthy women ageing between 20 and 92 years. Muscle mass was estimated by means of dual energy x-ray absorptiometry (DEXA).

Results: Appendicular skeletal muscle mass adjusted for height and total skeletal muscle mass adjusted for height were positively associated with BMI. Overweight women (BMI < 30.00) had a significantly reduced risk to develop sarcopenia in comparison with their normalweight counterparts.
\end{abstract}

Main conclusions: Mild overweight has a protective effect against muscle loss and sarcopenia in healthy women.

Keywords: Obesity, sacropenia, lean body mass, ageing.

\section{INTRODUCTION}

Sarcopenia, the decline in skeletal muscle mass in combination with higher fat accumulation in the muscle and lower muscle strength is considered as one of the hallmarks of human aging process [1]. The term sarcopenia, from the Greek "Poverty of flesh", was introduced by Rosenberg twenty years ago. Even today sarcopenia is mostly seen as a somatic condition typical of old aged people $[2,3]$. A condition which inevitably leads to an impaired functional performance, increased physical disability, vulnerability and frailty and an increased risk for falls [4,5]. Frail elderly people have not only an increased tendency to fall but also to break bones due to these falls and so sarcopenia results often in helplessness and in the loss of independence [6]. But sarcopenia and the loss of skeletal muscle mass do not appear during old age only. The decline of muscle mass starts very early, during the third decade of life and progresses thereafter [7]. As Lexell et al. [8] pointed out in human vastus lateralis sarcopenia starts during the mid twenties leading to $10 \%$ loss of muscle area by the age of 50 and $50 \%$ loss by the age of 80 years. With increasing age this loss in lean body mass accelerates and results in a deficiency of relative skeletal muscle mass $[7,9,10]$. The consequences of this process are dramatic ones because skeletal muscle represents not only the largest component at the tissue-organ level of body composition in healthy adults, it is also essential for physical activity [11]. Many different factors are discussed to promote

*Address correspondence to this author at the Department for Anthropology, University of Vienna, Althanstrasse 14, A-1090 Vienna, Austria; Tel: 0043 14277 54712; Fax: 004314277 9547;

E-mail: sylvia.kirchengast@univie.ac.at the loss of skeletal muscle mass. Beside a genetic predisposition, physical inactivity, a sedentary life style, nutritional factors, nicotine consumption, the loss of motoneurons, in women endocrine changes such as the decline of sex steroids associated with menopause and impairments in the growth hormone/IGF-I pathway are discussed to promote development and progression of sarcopenia [12-19]. One open question is still the effect of weight status on the development of sarcopenia. The effects of weight status on lean body mass are still discussed controversial. On the one hand a high weight status, first of all obesity is seen a special risk factor for the development of sarcopenia because obesity is often associated with a greater probability of functional limitations [20-22]. Furthermore it was pointed out that higher weight status and or weight stability may mask a dramatic decline in muscle mass [23]. Recently the term sarcopenic obesity was introduced into scientific literature considering the observation that obesity and sarcopenia may potentiate each other and so maximize their effects on physical disability, morbidity and mortality in advanced age [24,25]. On the other hand weight status is positively associated with bone density and bone mass. Several studies have shown that a low BMI represents a risk factor for osteopenia, osteoporosis and fractures [26-29], while obese individuals show an increase not only in bone mass but also lower body lean body mass, presumably an adaptive response that maintains mobility [28]. Therefore the aim of the present study was the analyses of the impact of weight status on skeletal muscle mass and the prevalence of sarcopenia in healthy women aging between 20 and 92 years. 


\section{MATERIAL AND METHODOLOGY}

\section{Subjects}

834 subjects ranging in age from 20 to 92 years $(x=50.1 \pm 14.6)$ were enrolled in the present study. All subjects were recruited by newspaper advertising, broadcasting or via snowball system and originated from Vienna or neighboring Lower Austria. The examination took place at the Menox-out-patient-department for the treatment of climacteric symptoms in Vienna. The examination started an extensive anamnesis and documentation of individual case history, reproductive history, previous diseases, surgery, actual and past medication. In a first step all subjects with acute diseases or a history of chronic or metabolic bone disease, physical disabilities and a treatment with drugs that may influence lean soft tissue and bone mass such as cortisone treatment were excluded from further analyses. Furthermore smoking was a strict exclusion criterion. In a second step the physical activity of the probands were documented using the questionnaire of habitual physical activity by Baecke et al. [30] None of the subjects had a history of excessive sportive activity or severe habitual physical activity during work, but all subjects were active and the elderly ones did not need care. All of them lived in private homes and not in geriatric homes for elderly people. Therefore the sample consists exclusively of healthy and mobile subjects. This selection was necessary because the aim of the study was to analyze the impact of weight status on sarcopenia exclusively. Therefore the authors tried to choose a homogeneous sample with as few as possible covariates which may influence the development of sarcopenia. Immobile subjects, especially elderly ones with a drastically impaired mobility, may increase the heterogeneity of the sample. Socioeconomic status was estimated by marital status, educational level, profession, family income and the area living in Vienna. All subjects belonged to the typical social middle class of urban Vienna. Therefore socioeconomic parameters were not considered in the further analyses. Beside the objectives of the study, the right to withdraw at any time was explained. Strict confidential was ensured. The study was conducted in compliance with "Ethical principles for medical research involving human subjects" of Helsinki Declaration and was approved by the Menox bioethical committee.

\section{Anthropometrics and Body Composition Analyses}

Stature height and body weight were determined according to the methods described in Knussmann [31]. Body composition analyses were performed by dual-energy-x-ray absorptiometry (DEXA) using a Hologic 4000 scanner. DEXA measures total bone mineral content (BMC) and bone density (BD), fat mass and lean soft tissue mass with a precision (coefficient of variation) of $0.9,4.7$ and $1.5 \%$ respectively. The precision of abdominal fat mass and fat $\%$ is $4.3 \%$ and $3.4 \%$ respectively [32]. All scans were obtained by the same person. The extinction of x-rays dependent on the tissue measured and absolute and relative fat mass and lean body mass are estimated. The scanner uses a x-ray source, an internal wheel to calibrate BMC and a external luciate and aluminium phantom to determine the percentage of fat of each soft tissue sample scanned. The percentage of body fat is determined from the ratio of attenuation of the lower energy $(70 \mathrm{kVp})$ to that of higher energy $(140 \mathrm{kVp})$ of the beam. This is calculated for all non skeleton pixels. The scan time takes approximately 6 minutes and the radiation doses are relatively low, with $.1 \mathrm{mSievert}$. Default software readings provide lines positioned to divide separate body compartments such as head, upper and lower limbs and trunk.

Appendicular skeletal muscle mass (ASM) was determined by combining the lean tissue mass of the regions of the arms and legs, excluding all other regions from analyses [33]. ASM was adjusted for height by dividing each mass by the square of height (metres squared), in this way the relative appendicular skeletal mass (RASM) was calculated. Additionally total skeletal mass (TSM) was estimated by multiplying the ASM by 1.33 in accordance with the assumption that ASM represents $75 \%$ of the total skeletal mass [34]. Additionally TSM was also adjusted for height by dividing TSM by the square of height and so the relative total skeletal mass was calculated (RTSM). For the classification of sarcopenia the definition proposed by Baumgartner et al. [5] was used. According to Baumgartner et al. [5] an adjusted ASM (RASM) greater than 2 standard deviations below the sex specific mean from a young healthy reference population was classified as sarcopenia. For the present paper normative levels for adjusted ASM (RASM) were taken from Gallagher et al. [4] for white non Hispanic Caucasians. According to this study the cut-off values for sarcopenia were 5.45 for women.

\section{Weight Status}

Weight status was classified using the Body mass index categories published by the WHO [35]:

$$
\begin{aligned}
& \text { BMI }<16.00=\text { severe thinness } \\
& \text { BMI 16.00-16.99 = moderate thinness } \\
& \text { BMI 17.00-18.49 = mild thinness } \\
& \text { BMI 18.50 }-24.99=\text { normal range (normal weight) } \\
& \text { BMI 25.00-29.99= overweight } \\
& \text { BMI 30.00-39.99= obese Grade I } \\
& \text { BMI }>40.00=\text { obese Grade II }
\end{aligned}
$$

Only normal weight and overweight women were included in the present analyses, because obese individuals (BMI > 30.00) can not be considered to be healthy. Underweight women were also excluded from the present sample because only 10women exhibited a BMI below 18.50. These women however were extremely thin, their BMIs were blow 17.00 and can't be considered as healthy.

\section{Statistical Analyses}

Statistical analyses were carried out by using SPSS program version 16.0 [Microsoft Corp.]. After calculating descriptive statistics such as means, standard deviations, ranges of the body composition variables, oneway Anovas (Duncun tests) and student t-test were performed to test group differences with respect to their statistical significance. Chisquares and odds ratios were calculated. Linear and binary regression analyses were computed in order to test the impact of weight status and age on lean body mass and sarcopenia.

\section{RESULTS}

\section{Subject Characteristics}

Subject characteristics are listed in Table $\mathbf{1}$. As to be seen the age groups differed significantly in body weight, BMI 
Table 1. Subject Characteristics

\begin{tabular}{|c|c|c|c|c|c|}
\hline Age groups & Stature height $(\mathrm{cm})$ & Body weight (kg) & $\operatorname{RASM}\left(\mathrm{kg} / \mathrm{m}^{2}\right)$ & $\operatorname{RTSM}\left(\mathrm{kg} / \mathrm{m}^{2}\right)$ & BMI $\left(\mathrm{kg} / \mathrm{m}^{2}\right)$ \\
\hline & $\mathbf{x}$ SD & $\mathbf{x}$ SD & $\mathbf{x}$ SD & $\mathbf{x}$ SD & $\mathbf{x}$ SD \\
\hline$<30 \mathrm{yr}$ & $167.3 \pm 5.9$ & $65.2 \pm 16.4$ & $5.96 \pm 0.86$ & $7.92 \pm 1.16$ & $23.27 \pm 5.77$ \\
\hline $30-39 \mathrm{yr}$ & $166.1 \pm 5.8$ & $72.5 \pm 15.8$ & $6.11 \pm 0.85$ & $8.13 \pm 1.13$ & $26.33 \pm 5.76$ \\
\hline $40-49 \mathrm{yr}$ & $164.9 \pm 6.1$ & $73.1 \pm 14.5$ & $5.98 \pm 0.93$ & $7.95 \pm 1.23$ & $26.91 \pm 5.21$ \\
\hline $50-59 \mathrm{yr}$ & $164.9 \pm 5.6$ & $73.4 \pm 12.6$ & $5.93 \pm 0.72$ & $7.89 \pm 0.96$ & $27.02 \pm 4.59$ \\
\hline $60-69 y \mathrm{r}$ & $163.8 \pm 5.8$ & $74.7 \pm 12.4$ & $5.98 \pm 0.81$ & $7.96 \pm 1.08$ & $27.79 \pm 4.11$ \\
\hline $70-79 y \mathrm{r}$ & $162.2 \pm 5.6$ & $72.4 \pm 11.4$ & $5.92 \pm 0.74$ & $7.88 \pm 0.98$ & $27.56 \pm 4.12$ \\
\hline$>80 \mathrm{yr}$ & $160.5 \pm 4.2$ & $61.6 \pm 11.1$ & $5.81 \pm 0.78$ & $7.73 \pm 1.04$ & $23.92 \pm 4.25$ \\
\hline p-value & $<0.0001$ & $<0.0001$ & n.s. & n.s. & $<0.0001$ \\
\hline
\end{tabular}

Legende: RASM: Appendicular skeletal mass (in $\mathrm{kg}$ ) $/ \mathrm{m}^{2}$.

RTSM: Total skeletal mass (in $\mathrm{kg}$ ) $/ \mathrm{m}^{2}$.

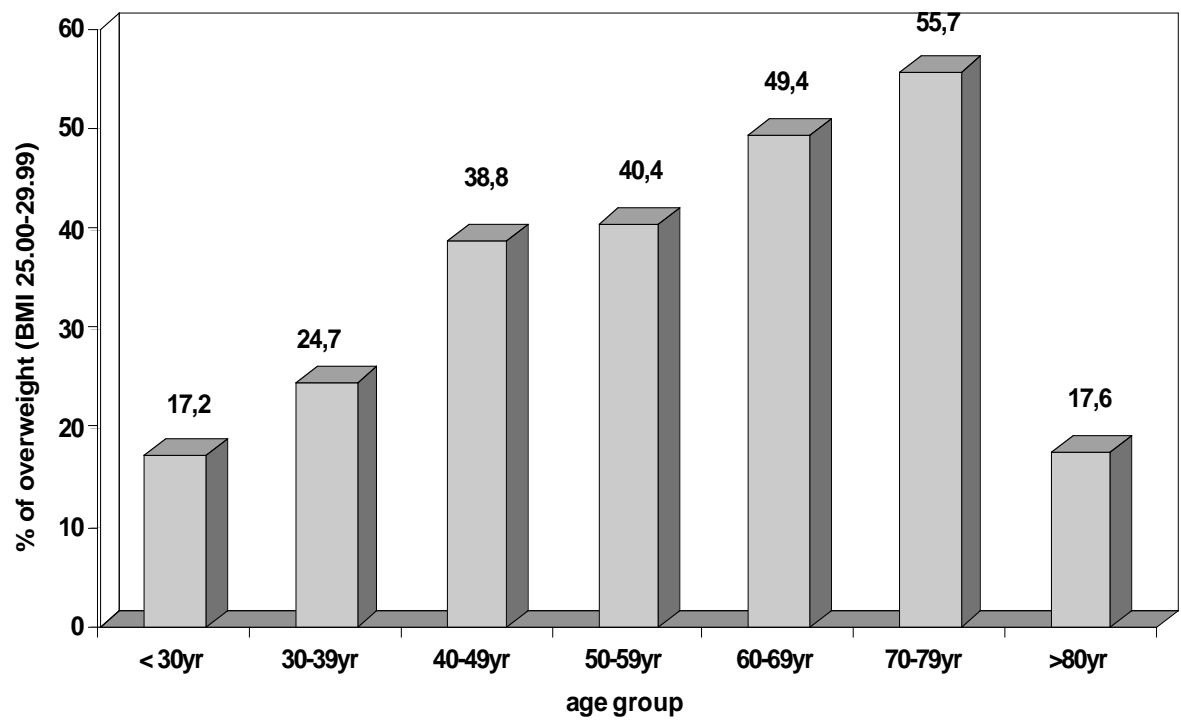

Fig. (1). Prevalence of overweight by age group.

and stature, while no significant differences in appendicular skeletal muscle mass adjusted for height and total skeletal muscle mass adjusted for height were found. Body weight well as BMI increased steadily up to the $70^{\text {th }}$ decade of life and decreased then. As to be seen in Fig. (1) the prevalence of overweight increased significantly $(\mathrm{p}<0.0001)$ with increasing age up to age group 70 to 79 years. $55.7 \%$ of the women aging between 70 and 79 years corresponded to the WHO definitions of overweight. Among the highest age group (> 80 years) however, only $17.6 \%$ of the subjects were classified as overweight.

\section{Skeletal Muscle Mass According to Weight Status and Age}

In this cross sectional study relative appendicular skeletal muscle mass (RASM) and relative total skeletal mass (RTSM) differed significantly according to weight status (see Table 2).

The amount of appendicular skeletal mass adjusted for height and total skeletal mass adjusted for height were sig- nificantly higher among overweight women in comparison with their normal weight counterparts. This was true of all age groups. A linear decline of appendicular skeletal mass adjusted for height and total skeletal mass adjusted for height however could neither be proved for overweight nor for normal weight women.

\section{Weight Status and Sarcopenia}

At first we had to state that the prevalence of sarcopenia was extraordinary high in the present sample. The prevalence of sarcopenia differed significantly between normal weight and overweight women $(\mathrm{p}<0.001)$. Normal weight women of each age group showed the significantly highest prevalence of sarcopenia (see Table 3). Furthermore the risk to develop sarcopenia was significantly higher among normal weight women in comparison with their overweight counterparts. This was true of all age groups however the odds ratio decreased with increasing age group (see Table $\mathbf{3}$ ).

The significant impact of weight status on appendicular skeletal mass adjusted for height and total skeletal mass 
Table 2. Relative Muscle Mass According to Age and Weight Status

\begin{tabular}{|c|c|c|c|}
\hline Age groups & & & $\mathrm{p}$ \\
\hline \multicolumn{4}{|l|}{$19-29$ yr $(n=99)$} \\
\hline RelASM & $5.65(0.56)$ & $6.55(0.73)$ & 0.0001 \\
\hline \multicolumn{4}{|l|}{$30-39$ yr $(n=89)$} \\
\hline RelASM & $5.69(0.62)$ & $6.47(0.86)$ & 0.0001 \\
\hline RelTSM & $7.57(0.83)$ & $8.59(0.77)$ & 0.0001 \\
\hline \multicolumn{4}{|l|}{$50-59$ yr $(n=276)$} \\
\hline RelASM & $5.52(0.55)$ & $6.15(0.74)$ & 0.0001 \\
\hline RelTSM & $7.35(0.74)$ & $8.19(0.92)$ & 0.0001 \\
\hline \multicolumn{4}{|l|}{$60-69$ yr $(n=87)$} \\
\hline RelASM & $5.37(0.61)$ & $6.16(0.78)$ & 0.0001 \\
\hline RelTSM & $7.14(0.81)$ & $8.19(0.98)$ & 0.0001 \\
\hline \multicolumn{4}{|l|}{$70-79$ yr $(n=62)$} \\
\hline
\end{tabular}

Table 3. Prevalence of Sarcopenia According to Weight Status and Age Group

\begin{tabular}{|c|c|c|c|c|c|c|c|}
\hline Age Groups & Prevalence & Odds Ratio & 95\% Confidence Interval & Prevalence & Odds Ratio & 95\% Confidence Interval & P Value \\
\hline $19-29 \mathrm{yr}$ & $28.3 \%$ & 5.32 & $1.36-20.91$ & $5.9 \%$ & 0.67 & $0.54-0.82$ & 0.0001 \\
\hline $30-39 \mathrm{yr}$ & $38.5 \%$ & 4.93 & $1.81-13.38$ & $12.8 \%$ & 0.63 & $0.48-0.83$ & 0.0001 \\
\hline $50-59$ yr & $52.6 \%$ & 3.19 & $2.12-4.82$ & $15.3 \%$ & 0.62 & $0.51-0.75$ & 0.0001 \\
\hline $60-69 \mathrm{yr}$ & $55.3 \%$ & 3.07 & $1.61-5.87$ & $25.4 \%$ & 0.55 & $0.33-0.90$ & 0.0001 \\
\hline $70-79 \mathrm{yr}$ & $57.1 \%$ & 2.73 & $1.28-5.79$ & $23.9 \%$ & 0.58 & $0.33-1.02$ & 0.01 \\
\hline$>80 \mathrm{yr}$ & $56.4 \%$ & 2.08 & $0.32-13.61$ & $30.0 \%$ & 0.83 & $0.45-1.51$ & n.s. \\
\hline
\end{tabular}


Table 4. Regression Analyses

\begin{tabular}{|c|c|c|c|}
\hline & Regression Coefficient B & Significance p-Value & 95\% Confidence Interval \\
\hline \multicolumn{4}{|c|}{ Dependent variable Relative Appendicular skeletal muscle mass (RASM) } \\
\hline BMI & 0.10 & 0.0001 & $0.094-0.116$ \\
\hline age & -0.01 & 0.003 & $-0.008--0.002$ \\
\hline \multicolumn{4}{|c|}{ Dependent variable Relative Total skeletal muscle mass (RTSM) } \\
\hline BMI & 0.14 & 0.0001 & $0.125-0.155$ \\
\hline \multicolumn{4}{|c|}{ Dependent variable sacropenia } \\
\hline BMI & -0.31 & 0.0001 & $0.682-0.785$ \\
\hline age & 0.02 & 0.03 & $1.001-1.029$ \\
\hline stature & -0.04 & 0.04 & $0.931-0.998$ \\
\hline
\end{tabular}

adjusted for height as well as on sarcopenia was corroborated by the results of the multiple and binary logistic regression analyses (see Table 4).

With increasing BMI appendicular skeletal mass adjusted for height and total skeletal mass adjusted for height increased significantly. This was also true of stature height. Age in contrast had a significantly negative impact on appendicular skeletal mass adjusted for height and total skeletal mass adjusted for height. Sarcopenia in contrast, was significantly negatively related to the BMI and stature height, but age had a significantly positive impact on the development of sarcopenia.

\section{DISCUSSION}

During the ageing process the human body undergoes profound changes in body composition. Beside the general weight gain two significant alterations are observable: on the one hand there is a shift towards more body fat mass, especially the accumulation of abdominal fat deposits and visceral fat mass, on the other hand there is a gradual loss of skeletal muscle mass and bone mass [36,37]. These body composition changes start relatively early, in the third and fourth decade of life, and continue up to old age [8,9]. While the adverse health effects of bone loss and the increase in fat mass often in combination with the development of overweight and obesity are well known since a long time [20,38], the dramatic disabilities associated with the gradual reduction of skeletal muscle mass are discussed only since about twenty years $[39,40]$. The term sarcopenia for description of this progressive depletion of muscle mass and muscle strength was introduced in 1989 into scientific literature. This condition effects health and well being in a twofold manner: sarcopenia leads to increased disability and frailty and to an increased risk of falls [41-44]. Especially the combination of sarcopenia and osteoporosis increases the frequency bone fractures and so the risk of helplessness and disability in old age $[6,44,45]$. On the other hand we have also be aware that muscle is a metabolically active tissue [46-49] and sarcopenia may therefore also contribute to the development of some of the metabolic disorders associated with aging [17]. Therefore it is important to identify all risk factors which enhance the decline of skeletal muscle mass. The best recognized extrinsic risk factors for the development of sarcopenia but also ostopenia and osteoporosis are decreased physical activity, nicotine consumption and nutritional factors [13-16,50]. But there are also some intrinsic factors involved in the ageing process of skeletal muscle: the decline of sex steroids, especially in human females after menopause, growth hormone, growth factors and metabolic processes such as glucose or fatty acid metabolism are of importance [47,49]. One special factor influencing the changes in fat free body mass seems to be weight status. Weight status, estimated by body mass index, tends to increase through the ageing process, and the development of overweight and obesity during the fifth or sixth decade of life are common in the majority of industrialized countries [38]. The effect of weight status on lean body mass, however, is discussed controversial. While a positive association between weight status and bone density was proved in several studies [26-29,51] a positive effect of weight status on muscle mass 
was not described. In contrast, obesity is described as a condition characterized by a reduced physical activity and a sedentary lifestyle. This life style promotes muscle loss and the development of sarcopenia. In the present study the association between body mass index and skeletal muscle mass was analyzed in healthy women ageing between 20 and 92 years. Since only healthy women should be included into the sample obese subjects were excluded. It turned out, that overweight women (BMI between 25.00 and 29.99) showed a significantly higher appendicular skeletal muscle mass adjusted for height as well as a higher total skeletal muscle mass adjusted for height. This was true of all age groups. The risk to develop sarcopenia was significantly increased in normalweight women in comparison with their overweight counterparts. According to the results of the present study the BMI had a positive impact on muscle mass. On the one hand this observation may be due to an adaptive response that maintains mobility and an increasing training effect [28]. On the other hand overweight women exhibit also a higher amount of subcutaneous fat tissue and subcutaneous fat tissue is also a source of sex steroids [52,53]. Especially during menopausal transition a higher amount of fat tissue is associated with higher levels of estrogens because the extraovarian estrogen synthesis, the conversion of androgens to estrogens takes place in the subcutaneous fat tissue [52-55]. This effect may decrease the effects of hormonal changes which are known to enhance the decrease of muscle mass. At a first glance these results are in sharp contrast to the description of the sarcopenic obesity [24,25], a condition which combine sarcopenia and obesity. But we have to be aware that only healthy overweight but not obese women were included in the present study. None of the subjects had a BMI above 30.00. All subjects were physically active, although none had a history of excessive sportive activity. Therefore none of them corresponded to the definitions of sarcopenic obesity. The results of the present study plead for a positive effect of mild overweight on muscle mass comparable to the positive interaction between BMI and bone density. However we have to interpret the results of the present study very critically: The prevalence of sarcopenia was extraordinary high in the present sample. More than $25 \%$ of the normal weight women aging between 20 and 29 years corresponded to the definitions of sarcopenia published by Baumgartner et al. [5]. Although Baumgartner et al. [5] also found a prevalence of sarcopenia of $23.1 \%$ among non-Hispanic white women younger than 70 years, the results of the present study plead for a critical discussion of existing sarcopenia definitions and frequently used cutoffs and may be for the development of new cut offs for the definition of sarcopenia for central European populations. It seems that the use of US American cut offs for European populations is limited -as pointed out be Tichet $e t$ al. [56], although the definitions of Baumgartner et al. [5] are listed in the recent Report of the European Working Group on sarcopenia in older people [57].

\section{ACKNOWLEDGEMENTS}

The authors are gratefully indebted to the Menox outpatient department for its kind cooperation. Special thanks go to the probands for their cooperation. The project was financially supported by the Hochschul-Jubiläumsfond (Project number:1667/2006).

\section{REFERENCES}

[1] Pahor M, Manini T, Cesari M. Sarcopenia: clinical evaluation, biological markers and other evaluation tools. J Nutr Health Aging 2009; 13: 724 .

[2] Abellan Van Kan G. Epidemiology of sarcopenia. J Nutr Health Aging 2009; 13: 708.

[3] Doherty TJ. Aging and saropenia. J Appl Physiol 2003; 95: 1717.

[4] Gallagher D, Visser M, de Meersman RE, et al. Appendicular skeletal muscle mass: effects of age, gender and ethnicity. J Appl Physiol 1997; 83: 229.

[5] Baumgartner RN, Koehler KM, Gallagher D, et al. Epidemiology of sarcopenia among the elderly in New Mexico. Am J Epidemiol 1998; 147: 755

[6] Mühlberg W, Sieber C. Sarcopenia and frailty in geriatric patients: implications for training and prevention. Z Gerontol Geriatr 2004; 37: 2 .

[7] Janssen I, Heymsfield S, Wang ZM, Ross R. Skeletal muscle mass and distribution in 468 men and women aged 18-88yr. J Appl Physiol 2000; 89: 81 .

[8] Lexell J, Taylor CC, Sjostrom M. What is the cause of the ageing atrophy Total number, size and proportion of different fiber types studied in whole VL muscle from 15 to 83 years old men. J Neurol Sci 1988; 84: 275-94.

[9] Kyle UG, Genton L, Hans D, Karsegard L, Slosman DO, Pichard C. Age-related differences in fat free mass, skeletal muscle, body cell mass and fat mass between 18 and 94 years. Eur J Clin Nutr 2001; 55: 663 .

[10] Tanko LB, Movsesyan L, Mouritzen U, Christiansen C, Svendsen OL. Appendicular lean tissue mass and the prevalence of sarcopenia among healthy women. Metabolism 2002; 51: 69.

[11] Wang Z, Heo M, Lee RC, Kotler DP, Withers RT, Heymsfield SB. Muscularity in adult humans: Proportion of adipose tissue -free body mass as skeletal muscle. Am J Hum Biol 2001; 13: 612.

[12] Kim JS, Wilson JM, Lee SR. Dietary implications on mechanisms of sarcopenia: roles of protein, amino acids and antioxidants. J Nurt Biochem 2009 (in press)

[13] Boire Y. Physiopathological mechanism of sarcopenia. J Nutr Health Aging 2009; 13: 717

[14] Bautmans I, Van Puyvelde K, Mets T. Sarcopenia and functional decline: pathophysiology, prevention and therapy. Acta Clin Belg 2009; 64: 303.

[15] Wilson MMG, Morley JE. Aging and energy balance. J Appl Physiol 2003; 95: 1728.

[16] Fujita S, Volpi E. Nutrition and sarcopenia of ageing. Nutr Res Rev 2004; 17: 69.

[17] Castillo EM, Goodman-Gruen D, Kritz-Silverstein D, Morton DJ, Wingard DL, Barrett-Connor E. Sarcopenia in elderly men and women. The Rancho Bernardo Study. Am J Prev Med 2003; 25: 226.

[18] Sörensen MB, Rosenfalck AM, Kojgaard L, Ottesen B. Obesity and sarcopenia after menopause are reversed by sex hormone replacement therapy. Obes Res 2001; 9: 622.

[19] Szulc P, Duboeuf F, Marchand F, Delmas PD. Hormonal and life style determinants of appendicular skeletal muscle mass in men: the MINOS study. Am J Clin Nutr 2004; 80: 496.

[20] Jensen GL, Hsiao PY. Obesity in older adults: relationship to functional limitation. Curr Opin Clin Metab Care 2010; 13(1): 46-51.

[21] Baumgartner RN, Wayne SJ, Waters DL, Janssen J, Gallagher D, Morley JE. Sarcopenic obesity predicts instrumental activities of daily living disability in the elderly. Obes Res 2004, 12: 1995.

[22] Zoico E, Di Francesco V, Guralnik JM, et al. Physical disability and muscular strength in relation to obesity and different body composition indexes in a ample of healthy elderly women. Int $\mathbf{J}$ Obes 2004; 28: 234.

[23] Gallagher D, Ruts E, Visser M, et al. Weight stability masks sarcopenia in elderly men and women. Am J Physiol Endcrinol Metab 2000; 279: E366.

[24] Stenholm, Marris TB, Rantanen T, Visser M, Kritchevsky SB, Ferrucci L. Sarcopenic obesity - definition, etiology and consequences. Curr Opin Clin Nutr Metab Care 2008; 11: 693.

[25] Zamboni M, Mazzali G, Fantin F, Rossi, Di Francesco V. Sarcopenic obesity: A new category of obesità in elderly. Nutr Metab Cadiovasc Dis 2008; 18: 388.

[26] Reid IR. Relationships among body mass, its components and bone. Bone 2002; $31: 547$. 
[27] Laet de C, Kanis JA, Oden A, et al. Body mass index as a predictor of fracture risk: a meta-analysis. Osteoporos Int 2005; 16: 1330.

[28] Leslie WD. Elevated bone mass: a weighty matter? Skeletal Radiol 2008; 37: 1063 .

[29] Asomaning K, Bertone-Johnson ER, Nasca PC, Hooven F, Pekow PS. The association between body mass index and osteoporosis in patients referred for a bone mineral density examination. J Women's Health 2006; 15: 1028.

[30] Baecke JAH, Burema J, Frijters JER. A short questionnaire for the measurement of habitual physical activity in epidemiological studies. Am J Clin Nutr 1982; 36: 936.

[31] Knussmann R, Somatometrie. In:. Knussmann R, Ed. Anthropologie. Stuttgart Fischer Verlag: USA 1988; 232.

[32] Svendsen O, Hassager C, Christiansen C. Age and menopause associated variations in body composition and fat distribution in healthy women measured by dual-energy $\mathrm{x}$-ray absorptiometry. Metabolism 1995; 44: 369.

[33] Heymsfield SB, Smith R, Aulet M, et al. Appendicular skeletal muscle mass: measurement by dual-photon absorptiometry. Am $\mathrm{J}$ Clin Nutr 1990; 52: 214.

[34] Wang ZM, Visser M, Ma R, et al. Skeletal muscle mass: Evaluation of neutron activation and dual energy x-ray absorptiometry methods. J Appl Physiol 1996; 80: 824.

[35] Obesity: Preventing and Managing the Global Epidemic World Health Organization, Geneva, 1997.

[36] Zamboni M, Zoico E, Sartezzini T, et al. Body composition changes in stable-weight elderly subjects: the effect of sex. Aging Clin Exp Res 2003; 15: 321-27.

[37] Harris TB. Body composition in studies of aging: new opportunities to better understand health risks associated with weight. Am J Epidemiol 2002; 156: 122.

[38] Bray GA. Medical consequences of obesity. J Clin Endocinol Metab 2004; 89: 2583.

[39] Greenlund LJS, Nair KS. Sarcopenia - consequences, mechanism and potential therapies. Mech Aging Dev 2003; 124: 287.

[40] Iannuzzi-Sucich M, Prestwood KM, Kenny AM. Prevalence of sarcopenia and predictors of skeletal muscle mass in healthy, older men and women. J Gerontol 2002; 57: 772.

[41] Fulle S, Belia S, Di Tano G. Sarcopenia is more than a muscular deficit. Arch Ital Biol 2005; 143: 229.

[42] Evans WJ, Campbell WW. Sarcopenia and age-related changes in body composition and functional capacity. J Nutr 1993; 123: 465.
[43] Lauretani F, Russo CR, Bandinelli S, et al. Age associated changes in skeletal muscles and their effect on mobility: an operational diagnosis of sarcopenia. J Appl Physiol 2003; 95: 1851.

[44] Szulc P, Beck TJ, Marchand F, Delmas PD. Low skeletal muscle mass is associated with poor structural parameters of bone and impaired balance in elderly men - the MINOS study. J Bone Mineral Res 2005; 20: 721 .

[45] Walsh MC, Hunter GR, Livingstone MB. Sarcopenia in premenopausal and postmenopausal women with osteopenia, osteoporosis and normal bone mineral density. Osteoporos Int 2006; 17: 61.

[46] Dupont-Versteegden EE. Apoptosis in muscle atrophy: relevance to sarcopenia. Experiment Gerontol 2005; 40: 473-81.

[47] Carmeli E, Coleman R, Reznick AZ. The biochemistry of aging muscle. Exper Gerontol 2002; 37: 477.

[48] Goldspink G, Harridge SDR. Growth factors and muscle ageing. Exp Gerontol 2004; 39: 1433.

[49] Song MY, Ruts E, Kim J, Janumala I, Heymsfield S, Galagher D. Sarcopenia and increased adipose tissue infiltration of muscle in elderly African-American women. Am Clin Nutr 2004; 79: 874.

[50] Morley JE. Anorexia, Sarcopenia and aging. Nutrition 2001; 17: 660.

[51] Sun AJ, Heshka S, Heymsfield SB, Wang J, Perison RN, Gallagher D. Is there an association between skeletal muscle mass and bone mineral density among African-American, Asian-American and European-American women? Acta Diabetol 2003; 40: S309.

[52] Siiteri PK. Adipose tissue as a source of hormones. Am J Clin Nutr 1987; 45: 277.

[53] Rexford SA, Flier JS. Adipose tissue as an endocrine organ. Trends Endocr Metab 2000; 11: 327.

[54] Aloia JF, McGowan DM, Vaswani AN, Poss P, Cohn SH. Relationship of menopause to skeletal and muscle mass. Am J Clin Nutr 1991; 53: 1378 .

[55] Burger HG, Dudley EC, Robertson DM, Dennerstein L. Hormonal changes in the menopause transition. Rec Prog Horm Res 2002; 57 : 257

[56] Tichet J, Vol S, Goxe D, Salle A, Berrut G, Ritz P. Prevalence of sarcopenia in the French senior population. J Nutr Health Ageing 2008; 12: 202.

[57] Cruz-Jentoft AJ, Baeyens JP, Bauer JM, et al. Sarcopenia: European consensus on definition and diagnosis. Age Ageing 2010; 39: 412.

(c) Kirchengast and Huber; Licensee Bentham Open.

This is an open access article licensed under the terms of the Creative Commons Attribution Non-Commercial License (http://creativecommons.org/licenses/by-nc/3.0/) which permits unrestricted, non-commercial use, distribution and reproduction in any medium, provided the work is properly cited. 